\title{
The Effects of Commercial Freezing on Vitamin Concentrations in Spinach (Spinacia oleracea)
}

Konrad Samsel ${ }^{1,2, *}$ (D) and Abizar Meghani ${ }^{2,3,4}$ (D)
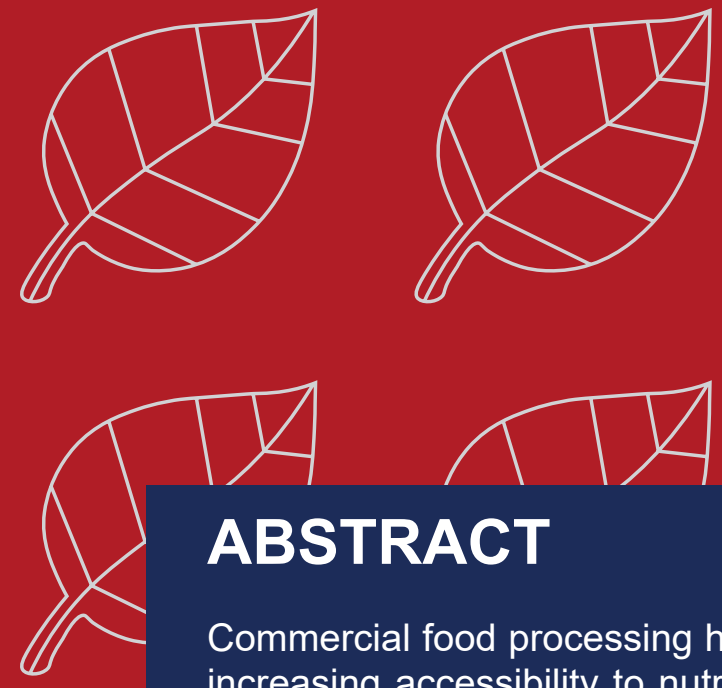

(a) processing has had a significant impact on reducing food spoilage and increasing accessibility to nutrient-dense vegetables. The commercial freezing process, in particular, has given producers the ability to store vegetables with minimized risk of microbial and enzymatic spoilage. Despite the effectiveness of freezing as a preservation method, there is evidence that pre-freezing procedures and prolonged storage can reduce the concentration of vitamins present within certain vegetables. Spinach, one of the most widely produced and consumed vegetables, is particularly susceptible to nutrient loss during the commercial freezing process due to its large surface area and high mineral content. This review summarizes the known effects of the freezing process on hydrophilic and lipophilic vitamins including vitamin $\mathrm{C}$, thiamin, riboflavin, $\beta$-carotene, and $\alpha$-tocopherol. There are two key mechanisms that lead to decreased vitamin concentrations, with the first being attributed to pre-freezing processes including washing and blanching which favours the leaching of hydrophilic vitamins. The second mechanism of vitamin loss is attributed to residual enzymatic activity during storage, where the degree of residual activity can be partially attributed to differences in blanching protocols and freezing practices. Understanding the mechanisms and extent of vitamin loss that the commercial freezing process imparts on leafy green vegetables can help inform future research on improved food processing methods that minimize nutrient loss. Implementing procedures that maintain nutrient retention in frozen vegetables has the potential to assist individuals in achieving their recommended daily intakes of micronutrients.

Keywords: Nutrients, Frozen Storage, Spinach, Vitamins, Ice Nucleation
Affiliations

${ }^{1}$ Department of Nutritional Sciences, University of Toronto, Canada

${ }^{2}$ Department of Ecology and Evolutionary Biology, University of Toronto, Canada

${ }^{3}$ Department of Physiology, University of Toronto, Canada

${ }^{4}$ Department of Physics, University of Toronto, Canada
${ }^{*}$ Please direct correspondence to:

Konrad Samsel

Email: konrad.samsel@mail.utoronto.ca

Published online on July 23, 2021 


\section{INTRODUCTION}

The commercial freezing process has allowed consumers to store foods for extended periods of time with minimal food spoilage ${ }^{1}$. Storing foods at sub-zero temperatures reduces enzyme activity, prevents microbial growth, and is one of the most effective preservation methods with regard to mitigating nutrient loss during prolonged storage ${ }^{2}$. Freezing as a preservation method has allowed yearround consumption of nutritious vegetables including spinach, which is known for its high amounts of vitamin $\mathrm{C}$, thiamin, riboflavin, $\beta$-carotene, and minerals such as iron and magnesium ${ }^{3}$.

Research suggests that pre-freezing processes and prolonged storage of spinach can result in considerable losses of vitamin C, thiamin, riboflavin, and $\beta$-carotene, and minor losses of $\alpha$-tocopherol| ${ }^{4-8}$. The observed large losses of water-soluble vitamins are mostly attributed to pre-freezing processes, namely blanching, which results in the leaching of vitamins and other soluble components of the food ${ }^{4,6}$. In this context, leaching can be defined as the loss or extraction of nutrients from the food by way of a fluid medium, namely water or condensed steam, that acts as a solvent. Prolonged storage at sub-zero temperatures has also been shown to augment vitamin loss, with the proposed mechanism being residual activity of enzymes involved in vitamin degradation ${ }^{9}$. This residual enzymatic activity can be increased by the process of freeze concentration, where enzymes and their substrates are concentrated within a fluid medium present between intracellular ice crystal formations $\mathrm{s}^{10}$. Decreases in vitamin concentrations in frozen spinach may have an impact on public health, with reduced vitamin levels affecting an individual's ability to reach their daily recommended intake (DRI) of nutrients. With an estimated $47 \%$ of young Canadian adults having suboptimal or deficient levels of serum ascorbic acid ${ }^{11}$ and $29-46 \%$ of Canadians not meeting their recommended daily allowance of vitamin $A^{12}$, identifying how vitamin concentrations decrease during commercial freezing can help inform future research on improved processing and storage methods that help individuals reach their nutritional requirements. This review will evaluate evidence related to the effects of the commercial freezing process on vitamin availability in spinach.

\section{BACKGROUND INFORMATION}

\section{Nutritional Composition of Spinach}

Spinach (Spinacia oleracea) is a commonly consumed commodity and is ingested and cultivated in many regions throughout the world ${ }^{13,14}$. There are numerous commercially available cultivars of spinach $^{14,15}$, each bred for beneficial qualities such as yield, organoleptic properties, or resistance to various biotic and abiotic conditions ${ }^{13,16}$. With regard to the nutritional content of fresh spinach, studies have found that variation can be influenced by several intrinsic and extrinsic factors including growing season, environmental conditions, and cultivar ${ }^{16-20}$. The representative values for fresh spinach provided by the United States Department of Agriculture show that it is a good source of vitamin C $(28.1 \mathrm{mg} / 100 \mathrm{~g})$, providing $31-37 \%$ of the DRI for adults ${ }^{3,21}$. This vegetable also contains $0.078 \mathrm{mg} / 100 \mathrm{~g}$ of thiamin, $0.189 \mathrm{mg} / 100 \mathrm{~g}$ of riboflavin, $469 \mu \mathrm{g} / 100 \mathrm{~g}$ of vitaminA, $5626 \mu \mathrm{g} / 100 \mathrm{~g}$ of $\beta$-carotene, and $2.03 \mathrm{mg} / 100 \mathrm{~g}$ of $\alpha$-tocopherol ${ }^{3}$. A 100-gram serving is thus expected to provide $7 \%$ of the DRI for thiamin, $15-17 \%$ for riboflavin, $52-67 \%$ for vitamin $\mathrm{A}$, and $14 \%$ for vitamin $\mathrm{E}$ in adults ${ }^{21}$. Determining these vitamin concentrations often involves homogenization of the spinach leaf and addition of the homogenate to a solute specific to the vitamin being measured ${ }^{6,7,22}$. After the solution containing the extract of the compound of interest is filtered, the sample is analyzed via high pressure liquid chromatography (HPLC) $)^{6,7,22,23}$. A protocol for ascorbic acid detection in spinach is detailed in Figure 1.

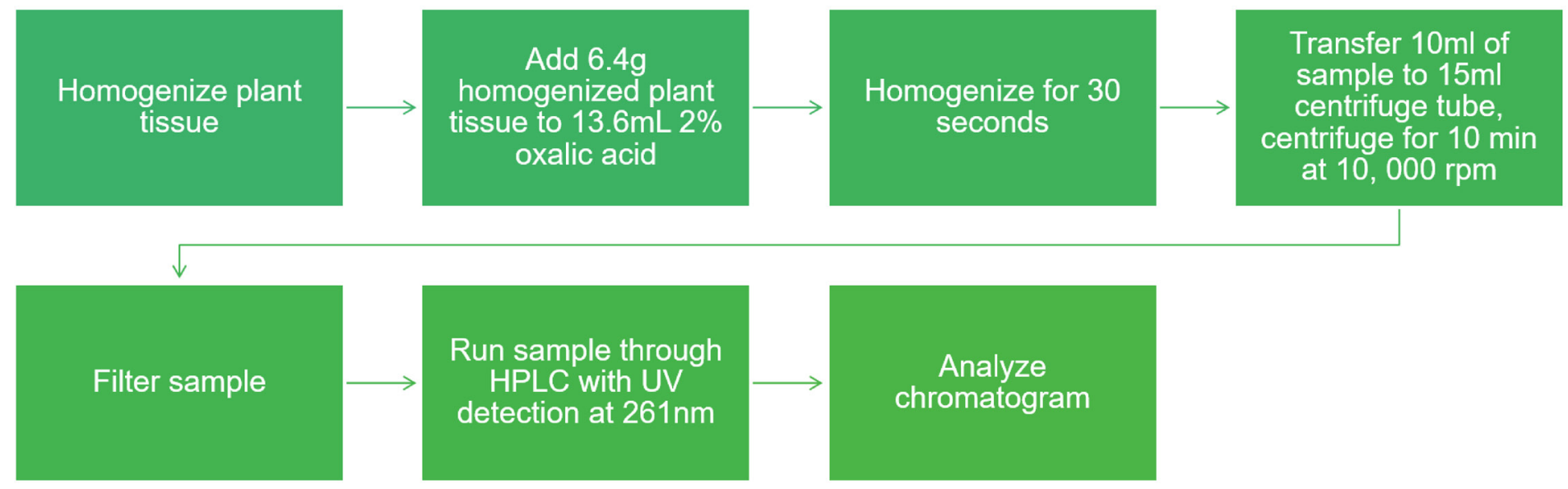

Figure 1 Protocol for ascorbic acid detection in spinach. Measurement protocol adapted from Bouzari et. al. ${ }^{6}$ 


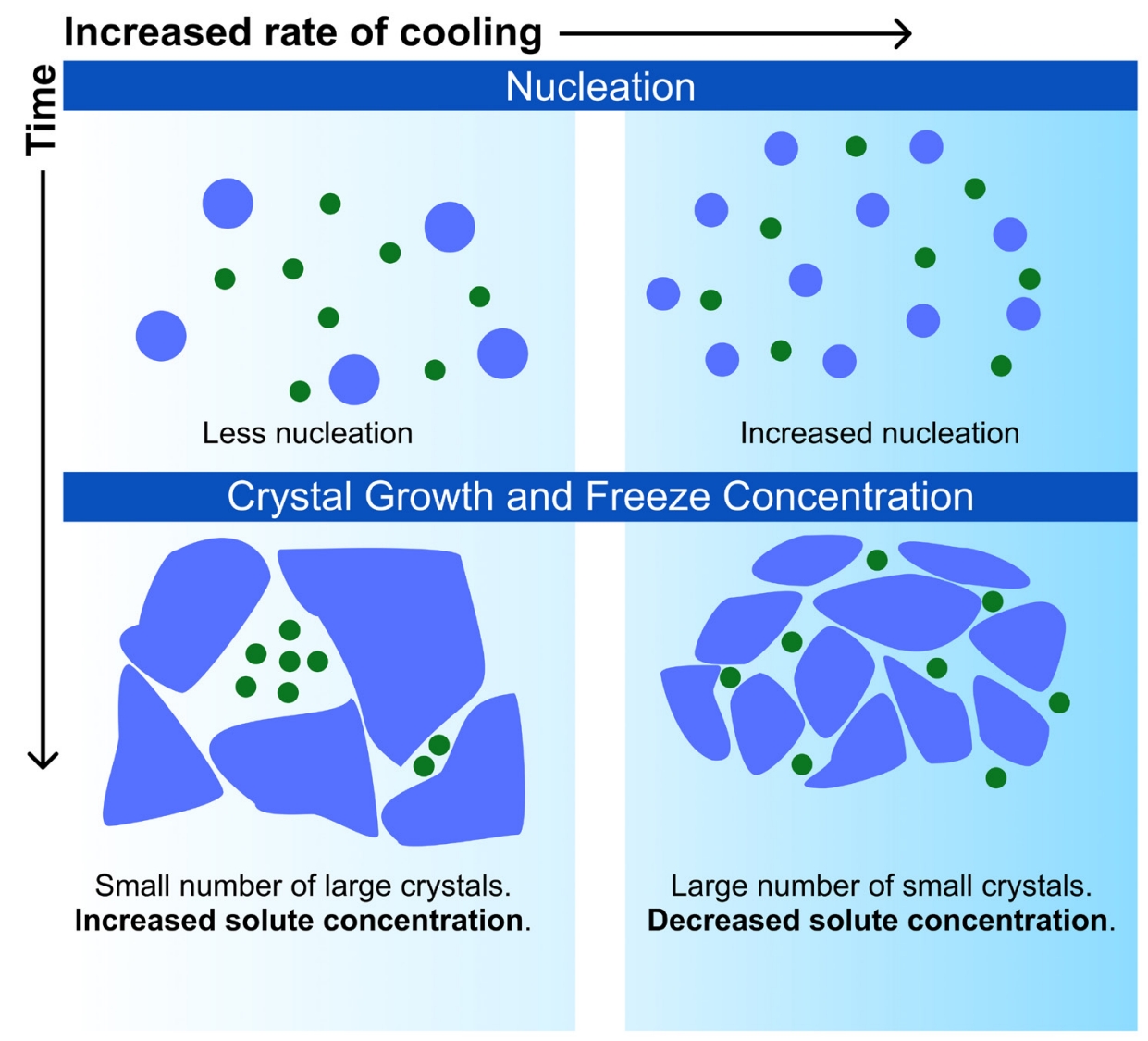

Figure 2 Impact of cooling rate on ice crystal formation and freeze concentration.

\section{Commercial Freezing Process of Spinach}

The commercial freezing process includes several pre-freezing steps to protect the quality and prevent spoilage of the final product. The most common prefreezing processes are washing and steam-based blanching. Blanching, which consists of a brief application of heat to food, helps preserve product quality by decreasing enzyme activity and microbial load $^{24}$. Enzymes present in the cellular components can affect the colour, taste, and nutritional quality of the vegetable following harvesting ${ }^{25}$. After the occurrence of cellular damage from picking and handling, these enzymes produce off-flavours, promote discolouring via enzymatic browning reactions, and promote vitamin degradation through enzyme induced oxidation ${ }^{25}$. The temperature at which a product is blanched strongly determines the degree of enzyme inactivation and subsequent residual enzymatic activity during storage. For example, studies examining the effects of blanching on ascorbic acid oxidase (AAO) activity in vegetables found that greater temperatures led to increased enzyme inactivation, helping to preserve vitamin C content within the food over time ${ }^{26,27}$. While spinach blanching time and temperature may vary, a steam blanch at $93.3^{\circ} \mathrm{C}$ for 3 minutes has been suggested to be an effective pre-freezing treatment ${ }^{6}$.
After blanching to reduce enzyme and microbial activity, the product is then rapidly frozen at temperatures around $-20^{\circ} \mathrm{C}$ to $-40^{\circ} \mathrm{C}^{28}$. Lower temperatures will cause rapid cooling of the product, resulting in increased numbers of ice crystal initiation sites, known as nuclei ${ }^{29,30}$. This increased nucleation will limit the growth and final size of the ice crystals ${ }^{29,30}$. One benefit of this finer crystal size is that it can help preserve the texture and taste of the spinach by minimizing freeze-concentration, which occurs when solutes are aggregated due to ice formation ${ }^{30}$. This physical process can increase substrate concentrations, increasing the kinetics of enzyme-mediated degradation reactions ${ }^{10}$. Preventing the formation of large ice crystals also helps minimize the likelihood of damage to cellular structures within the food. Damage to cellular structures affects the nutritional and textural qualities of frozen food by allowing the release of sequestered enzymes and by facilitating the loss of osmotic and turgor pressure ${ }^{28}$. This connection between cooling rate, nucleation, freeze concentration and crystal size is further depicted in Figure 2.

The frozen spinach is then stored at sub-zero temperatures until it is defrosted or cooked. The product often spends several months in commercial 
and residential storage conditions and is subsequently subjected to fluctuations in temperature ${ }^{7}$. Storage temperatures vary between appliances, with frozen food warehouses and distributors typically having freezer temperatures between $-20^{\circ} \mathrm{C}$ and $-25^{\circ} \mathrm{C}$, and residential freezers having temperatures around $15^{\circ} \mathrm{C}^{7}$. These differences in temperature, as will be examined later, may affect the activity of enzymes involved in vitamin degradation. An overview of a typical spinach freezing process is outlined in Figure 3.

\begin{tabular}{cl} 
Harvest & Harvest from field \\
\hline Blanch & Blanch at $93.3^{\circ} \mathrm{C}$ for $3 \mathrm{~min}$ \\
\hline Freeze & Rapidly freeze product at $-32^{\circ} \mathrm{C}$ for 1 hour \\
\hline Store & Store at sub-zero temperatures until needed \\
\hline Thaw/Cook & Thaw/Cook product \\
\hline
\end{tabular}

Figure 3 Commercial freezing process of Spinach. Freezing protocol adapted from Bouzari et. al. ${ }^{6}$

\section{PRESENTATION OF SCIENTIFIC DATA}

\section{Effects on ascorbic acid (vitamin C) concentrations}

There is evidence that the commercial freezing process greatly reduces the ascorbic acid content in spinach. In a study conducted by Tosun and Yücecan, spinach lost $46.1 \%$ and $57.9 \%$ ascorbic acid content when blanched in water for 140 seconds at $95^{\circ} \mathrm{C}$ and stored at $-18^{\circ} \mathrm{C}$ for 3 and 6 months, respectively ${ }^{8}$. Another study found that commercially frozen spinach had a $63 \%$ loss of ascorbic acid following a 105 second steam blanch and storage at $40^{\circ} \mathrm{C}$ until samples could be analyzed ${ }^{4}$. However, as the authors note, various variables such as growing season and inclusion of spinach stems in the homogenate when determining vitamin $\mathrm{C}$ content could have had an impact on the lower values observed. In contrast, a study conducted by Bouzari et al. found no significant differences in ascorbic acid content between fresh and frozen spinach, with only a $23 \%$ loss after blanching for 3 minutes at $93.3^{\circ} \mathrm{C}$ and storage for 3 months at $27.5^{\circ} \mathrm{C}^{6}$. A possible explanation for this difference may be attributed to the reduced storage temperature in this experimental protocol. Additionally, the authors of this study noted the use of a $32^{\circ} \mathrm{C}$ freezer for 1 hour following blanching ${ }^{6}$. The increased cooling rate of these samples may have further minimized losses by reducing the level of freeze-concentration.

It is important to note that the losse so ascorbic acid seen during prolonged storage at sub-zero temperatures are still significantly lower when compared to ambient and refrigerated storage ${ }^{9}$. In a study comparing vitamin $\mathrm{C}$ loss in spinach across these storage conditions, it was found that 12 months of frozen storage at $-20^{\circ} \mathrm{C}$ resulted in a $34 \%$ decrease in vitamin $\mathrm{C}$ concentration, whereas 7 days of refrigerated storage at $4^{\circ} \mathrm{C}$ resulted in an $80 \%$ decrease of this same nutrient ${ }^{9}$. Spinach reposited at an ambient temperature of $20^{\circ} \mathrm{C}$ experienced the highest rate of ascorbic acid loss, with a $90 \%$ reduction after 3 days.

Furthermore, these losses are not comparable across all frozen commodities. The results of a comparative analysis of ascorbic acid loss between different vegetables following a 60-day freezing process simulating a distribution-consumer cycle found that spinach had significantly higher losses of this nutrient ${ }^{7}$. While spinach experienced a $75.8 \%$ decrease in ascorbic acid under these conditions, losses in okra, peas, and green beans ranged from 25.6-47.8\%. Most of the vitamin $\mathrm{C}$ loss observed in spinach occurred during the prolonged storage phase at sub-zero temperatures, with a $6 \%, 11 \%$, and $41 \%$ loss after 10 , 20 , and 40 days respectively?

\section{Effects on soluble vitamin B concentrations}

Research examining water-soluble $B$ vitamins such as thiamin (B1) and riboflavin (B2) suggests that they are also susceptible to loss and degradation under the commercial freezing process. In one study, it was observed that there was a significant $51 \%$ loss of thiamin content and a $40 \%$ loss of riboflavin content in spinach that had been steam blanched for 105 seconds, frozen, and stored at $-40^{\circ} \mathrm{C}$ for varying lengths of time ${ }^{4}$. This was corroborated by Duyne et al., who found a $30-45 \%$ reduction in riboflavin content after spinach had been commercially frozen and stored at $-17.8^{\circ} \mathrm{C}$ $\pm 2.8^{\circ} \mathrm{C}$ for 20 hours $^{5}$.

\section{Effects on $\alpha$-tocopherol and $\beta$-carotene concentrations}

The effects of the commercial freezing process on fat soluble vitamins and vitamin precursors are less pronounced than effects on water soluble vitamins. Levels of a tocopherol, a type of vitamin E, do not seem to decrease by a significant amount after processing and freezing 6 . In fact, spinach that had undergone processing and freezing had 12-39\% higher levels of a-tocopherol compared to fresh spinach ${ }^{6}$. Heat treatment during processing is the likely mechanism by which levels increase. By reducing tocopherol oxidase activity and increasing a-tocopherol's release from lipids, availability has been shown to increase by $52 \%$ following blanching ${ }^{31}$.

Losses of $\beta$-carotene, a vitamin A precursor, seem to be dependent on freezing protocol, with studies having conflicting results ${ }^{6,23}$. When processed with a 3-minute steam blanch at $96^{\circ} \mathrm{C}$, followed by flashfreezing at $-40^{\circ} \mathrm{C}$ and storage at $-20^{\circ} \mathrm{C}$ for 6 months, concentrations of $\beta$-carotene were found to be $27 \%$ 
higher compared to fresh spinach ${ }^{23}$. This finding is likely due to a blanch mediated increase in availability as previously mentioned with $\alpha$-tocopherol. However, in a study using a lower steam-blanching temperature of $93^{\circ} \mathrm{C}$ for 3 minutes, followed by a flash-freeze temperature of $32^{\circ} \mathrm{C}, \beta$-carotene levels were found to have decreased by $54 \%$ when stored for 90 days at $-27.5^{\circ} \mathrm{C}^{6}$. This decrease may be attributed to the oxidation of $\beta$-carotene during storage ${ }^{6}$.

\section{MECHANISMS OF VITAMIN LOSS}

\section{Effects of pre-freezing treatment on vitamin content} Pre-freezing processes including washing and waterbased blanching are some of the major contributors to the reduction in water soluble vitamin concentrations in frozen spinach, specifically: ascorbic acid, thiamin, and riboflavin ${ }^{6,32}$. Additionally, the large surface area of the spinach leaf, compared to other vegetables, further aids in the leaching of these hydrophilic vitamins ${ }^{4}$. This water-based mechanism accounts for the observation that fat-soluble vitamins such as a-tocopherol do not decrease by a significant amount after processing ${ }^{6,33}$. Blanching duration and temperature are both factors influencing nutrient composition in foods, where lower temperatures and associated longer blanching times reduce hydrophilic vitamin concentrations in vegetables ${ }^{34-36}$. Alternative pre-freezing processes such as microwave blanching may be effective in mitigating nutrient loss while still facilitating enzyme inactivation ${ }^{37}$. Studies on other foods have found that this alternate form of blanching led to higher retentions of vitamin $\mathrm{C}$ and reduced ascorbic acid oxidase activity when compared to water-based blanching methods ${ }^{36,37}$. Despite these benefits, implementing this technology at an industrial level continues to face significant challenges, namely the nonuniform temperature distribution in large samples, which may lead to the occurrence of cold-spots ${ }^{38}$. There is a continued effort to improve the applicability of microwave assisted blanching to commercial freezing processes ${ }^{38}$.

\section{Effects of prolonged storage of spinach at sub- zero temperatures}

Although pre-freezing treatments have an influence on nutrient concentration, decreases in vitamin concentrations can further be attributed to residual enzymatic activity. Enzymes such as AAO, in the presence of sulfhydryl groups, copper, and ferric ion catalysts found within spinach, promote the degradation of vitamins during sub-zero storage ${ }^{7}$. While blanching helps to alleviate enzyme activity, it has been shown in plant models that residual enzymatic activity occurs even after pre-freezing processes, and continues during storage at sub-zero temperature ${ }^{39,40}$. For ascorbic acid, this loss has been demonstrated to follow first-order kinetics ${ }^{22}$. Potential mechanisms that may favour enzymatic activity during prolonged frozen storage include incomplete thermal enzyme inactivation ${ }^{39,40}$, enzyme reactivation ${ }^{41}$, and freeze concentration favouring increased enzymatic reaction rates ${ }^{10}$. Variations in storage temperature across retail and domestic freezer systems is likely an accompanying factor towards increased rates of enzyme mediated degradation ${ }^{7}$. Research conducted on ascorbic acid loss in spinach determined that an increase in sub-zero storage temperature led to an increase in residual enzymatic activity, which in turn was correlated with decreases in ascorbic acid concentrations ${ }^{9}$. A recent kinetic study quantified this impact, and found a 24-fold increase in the rate of vitamin $C$ degradation when spinach was stored at $-5^{\circ} \mathrm{C}$ in comparison to a reference storage temperature of $-18^{\circ} \mathrm{C}^{22}$. The kinetic modelling from this study also suggests that enzyme-mediated degradation varies with temperature in a logarithmic fashion, indicating that in industrial and retail environments, where temperatures are often below $-18^{\circ} \mathrm{C}$, further decreases in residual enzymatic activity may be observed. Similar enzymatic oxidative reactions may play a part in the degradation of other nutrients outlined in this article. An overview of mechanisms is described in Figure 4.

Recently, progress has been made in identifying new approaches that limit nutrient loss and preserve product quality during prolonged storage of food products ${ }^{28,42}$. There is promising evidence that alternative processing methods such as microwave assisted freezing and shock freezing may both promote ice nucleation ${ }^{28}$. The first investigation of microwave assisted freezing in food systems conducted in 2014 revealed it reduced crystal size by $62 \%$ in meat products when compared to conventional freezing techniques at the same temperature $\left(-30^{\circ} \mathrm{C}\right)^{43}$. Despite encouraging evidence of potentially reducing freeze-concentration, there has been no investigation into this technology's effects on nutrient composition in vegetables, including spinach ${ }^{44}$. Similar effects have been observed in shock freezing, also referred to as supercooled freezing ${ }^{45}$. In this process, a sample is first acclimated to near freezing temperatures, and then is rapidly exposed to subzero temperatures, leading to increased nucleation ${ }^{45}$. Further investigation into these technologies and their effects on nutrient loss during prolonged storage at sub-zero temperatures is needed before their adoption into large scale commercial use.

\section{LIMITATIONS}

A limitation of the literature cited in this review is the existence of considerable heterogeneity in processing and storage protocols across studies. Differences in blanching methods, in addition to variations in the rate of initial cooling, storage temperature, and storage time hinder the ability to compare results and identify causative factors of nutrient loss. Furthermore, 


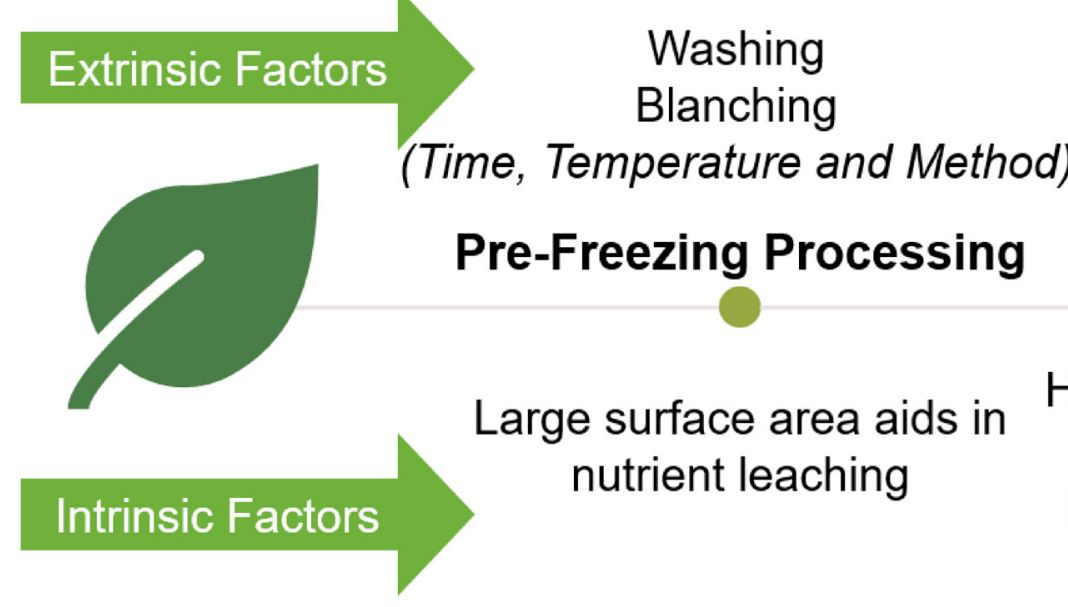

\author{
Rate of Cooling \\ Storage Temperature
}

Frozen Storage

High concentrations of thiols, copper and ferric ions increase enzymatic activity

Figure 4 Overview of extrinsic and intrinsic factors that influence vitamin loss in commercially frozen spinach.

confounding variables such as variations in growing conditions, maturity of the spinach leaves during harvest, and the duration of time between harvest and processing may further contribute to differences in results across studies ${ }^{9,46}$.

\section{CONCLUSION}

Most studies conducted to date suggest that commercial freezing processes, including pre-freezing treatments, decrease nutrient concentrations in spinach. In addition to washing and blanching, which induces the leaching of water-soluble vitamins, residual enzymatic activity in sub-zero temperatures further decreases vitamin content. Future research should be directed toward developing and evaluating improved processing methods that mitigate vitamin loss in spinach. With spinach being one of the most susceptible vegetables to vitamin loss due to its large surface area and ion content, it is essential that an ideal industrial freezing process be developed that helps mitigate its nutrient losses. Further investigation into the mechanisms of vitamin loss has the potential to inform the development of improved freezing processes that increase nutrient density and reduce the prevalence of micronutrient deficiencies.

\section{COMPETING INTERESTS}

No competing interests declared.

Received: November 28, 2020

Accepted: July 6, 2021

Published online: July 23, 2021

\section{REFERENCES}

1. Amit, S. K., Uddin, Md. M., Rahman, R., Islam, S. M. R. \& Khan, M. S. A review on mechanisms and commercial aspects of food preservation and processing. Agriculture \& Food Security 6, 51 (2017).

2. Devahastin, S. Physicochemical Aspects of Food Engineering and Processing - 7.2.4 Vitamins. (CRC Press, 2010).

3. U.S. Dept. of Agriculture, Agricultural Research Service, Beltsville Human Nutrition Research Center, Nutrient Data Laboratory. USDA national nutrient database for standard reference. FoodData Central https://fdc.nal.usda.gov/ (2019).

4. Gleim, E. G., Tressler, D. K. \& Fenton, F. Ascorbic acid, thiamin, riboflavin, and carotene contents of asparagus and spinach in the fresh, stored, and frozen states, both before and after cooking. Journal of Food Science 9, 471-490 (1944).

5. Duyne, F. O., Wolfe, J. C. \& Owen, R. F. Retention of Riboflavin in Vegetables Preserved by Freezing. Journal of Food Science 15, 53-61 (1950).

6. Bouzari, A., Holstege, D. \& Barrett, D. M. Vitamin Retention in Eight Fruits and Vegetables: A Comparison of Refrigerated and Frozen Storage. J. Agric. Food Chem. 63, 957-962 (2015).

7. Giannakourou, M. C. \& Taoukis, P. S. Kinetic modelling of vitamin $C$ loss in frozen green vegetables under variable storage conditions. Food Chemistry 83, 33-41 (2003).

8. Tosun, B. N. \& Yücecan, S. Influence of commercial freezing and storage on vitamin $\mathrm{C}$ content of some vegetables. International Journal of Food Science \& Technology 43, 316-321 (2008).

9. Favell, D. A comparison of the vitamin C content of fresh and frozen vegetables. Food Chemistry 62, 59-64 (1998).

10. Joslyn, M. A. Enzyme Activity in Frozen Vegetable Tissue. in Advances in Enzymology and Related Areas of Molecular Biology 613-652 (John Wiley \& Sons, Ltd, 1949). doi:10.1002/9780470122549.ch11.

11. Cahill, L., Corey, P. N. \& El-Sohemy, A. Vitamin C Deficiency in a Population of Young Canadian Adults. Am J Epidemiol 170, 464-471 (2009).

12. Shakur, Y. A., Tarasuk, V., Corey, P. \& O'Connor, D. L. A Comparison of Micronutrient Inadequacy and Risk of High Micronutrient Intakes among Vitamin and Mineral Supplement Users and Nonusers in Canada. J Nutr 142, 534-540 (2012).

13. Ribera, A., Bai, Y., Wolters, A.-M. A., van Treuren, R. \& Kik, C. A review on the genetic resources, domestication and breeding 
history of spinach (Spinacia oleracea L.). Euphytica 216, 48 (2020). 14. Roberts, J. L. \& Moreau, R. Functional properties of spinach (Spinacia oleracea L.) phytochemicals and bioactives. Food Funct. 7, 3337-3353 (2016).

15. Khattak, J. Z. K., Christiansen, J. L., Torp, A. M. \& Andersen, S. B. Genic microsatellite markers for discrimination of spinach cultivars. Plant Breeding 126, 454-456 (2007).

16. Howard, L. R., Pandjaitan, N., Morelock, T. \& Gil, M. I. Antioxidant Capacity and Phenolic Content of Spinach As Affected by Genetics and Growing Season. J. Agric. Food Chem. 50, 5891-5896 (2002). 17. Conte, A. et al. Influence of growing periods on the quality of baby spinach leaves at harvest and during storage as minimally processed produce. Postharvest Biology and Technology 50, 190196 (2008).

18. Weston, L. A. \& Barth, M. M. Preharvest factors affecting postharvest quality of vegetables. HortScience 32, 812-816 (1997). 19. Koh, E., Charoenprasert, S. \& Mitchell, A. E. Effect of organic and conventional cropping systems on ascorbic acid, vitamin C, flavonoids, nitrate, and oxalate in 27 varieties of spinach (Spinacia oleracea L.). J Agric Food Chem 60, 3144-3150 (2012).

20. Lester, G. E., Makus, D. J., Hodges, D. M. \& Jifon, J. L. Summer (Subarctic) versus Winter (Subtropic) Production Affects Spinach (Spinacia oleracea L.) Leaf Bionutrients: Vitamins (C, E, Folate, K1, provitamin A), Lutein, Phenolics, and Antioxidants. J. Agric. Food Chem. 61, 7019-7027 (2013).

21. Health Canada. Reference Values for Vitamins - Dietary Reference Intakes Tables. https://www.canada.ca/en/healthcanada/services/food-nutrition/healthy-eating/dietary-referenceintakes/tables/reference-values-vitamins-dietary-referenceintakes-tables-2005.html (2005).

22. Dermesonluoglu, E., Katsaros, G., Tsevdou, M., Giannakourou, M. \& Taoukis, P. Kinetic study of quality indices and shelf life modelling of frozen spinach under dynamic conditions of the cold chain. Journal of Food Engineering 148, 13-23 (2015).

23. Puupponen-Pimiä, R. et al. Blanching and long-term freezing affect various bioactive compounds of vegetables in different ways. Journal of the Science of Food and Agriculture 83, 1389-1402 (2003).

24. Xiao, H.-W. et al. Recent developments and trends in thermal blanching - A comprehensive review. Information Processing in Agriculture 4, 101-127 (2017).

25. Xin, Y., Zhang, M., Xu, B., Adhikari, B. \& Sun, J. Research trends in selected blanching pretreatments and quick freezing technologies as applied in fruits and vegetables: A review. International Journal of Refrigeration 57, 11-25 (2015).

26. Leong, S. Y. \& Oey, I. Effect of endogenous ascorbic acid oxidase activity and stability on vitamin $\mathrm{C}$ in carrots (Daucus carota subsp. sativus) during thermal treatment. Food Chemistry 134, 2075-2085 (2012).

27. Wawire, M. et al. Thermal Stability of Ascorbic Acid and Ascorbic Acid Oxidase in African Cowpea Leaves (Vigna unguiculata) of Different Maturities. J. Agric. Food Chem. 59, 1774-1783 (2011).

28. van der Sman, R. G. M. Impact of Processing Factors on Quality of Frozen Vegetables and Fruits. Food Eng Rev 12, 399_ 420 (2020).

29. Fernández, P. P., Otero, L., Guignon, B. \& Sanz, P. D. Highpressure shift freezing versus high-pressure assisted freezing: Effects on the microstructure of a food model. Food Hydrocolloids
20, 510-522 (2006).

30. Sánchez, J., Ruiz, Y., Auleda, J. M., Hernández, E. \& Raventós, M. Review. Freeze Concentration in the Fruit Juices Industry. Food sci. technol. int. 15, 303-315 (2009).

31. Lee, S., Choi, Y., Jeong, H. S., Lee, J. \& Sung, J. Effect of different cooking methods on the content of vitamins and true retention in selected vegetables. Food Sci Biotechnol 27, 333-342 (2017).

32. Davey, M. W. et al. Plant L-ascorbic acid: chemistry, function, metabolism, bioavailability and effects of processing. Journal of the Science of Food and Agriculture 80, 825-860 (2000).

33. Chun, J., Lee, J., Ye, L., Exler, J. \& Eitenmiller, R. R. Tocopherol and tocotrienol contents of raw and processed fruits and vegetables in the United States diet. Journal of Food Composition and Analysis 19, 196-204 (2006).

34. Severini, C., Giuliani, R., De Filippis, A., Derossi, A. \& De Pilli, $T$. Influence of different blanching methods on colour, ascorbic acid and phenolics content of broccoli. J Food Sci Technol 53, 501-510 (2016).

35. Priecina, L., Karklina, D. \& Kince, T. The impact of steamblanching and dehydration on phenolic, organic acid composition, and total carotenoids in celery roots. Innovative Food Science \& Emerging Technologies 49, 192-201 (2018).

36. Kachhadiya, S., Kumar, N. \& Seth, N. Process kinetics on physico-chemical and peroxidase activity for different blanching methods of sweet corn. J Food Sci Technol 55, 4823-4832 (2018). 37. Xanthakis, E., Gogou, E., Taoukis, P. \& Ahrné, L. Effect of microwave assisted blanching on the ascorbic acid oxidase inactivation and vitamin $\mathrm{C}$ degradation in frozen mangoes. Innovative Food Science \& Emerging Technologies 48, 248-257 (2018).

38. Dorantes-Alvarez, L., Ortiz-Moreno, A., Guzmán-Gerónimo, R. \& Parada-Dorantes, L. Microwave Assisted Blanching. in The Microwave Processing of Foods (Second Edition) (eds. Regier, M., Knoerzer, K. \& Schubert, H.) 179-199 (Woodhead Publishing, 2017). doi:10.1016/B978-0-08-100528-6.00009-7.

39. Rodriguez-Saona, L. E., Barrett, D. M. \& Selivonchick, D. P. Peroxidase and Lipoxygenase Influence on Stability of Polyunsaturated Fatty Acids in Sweet Corn (Zea mays L.) during Frozen Storage. Journal of Food Science 60, 1041-1044 (1995). 40. Bahçeci, K. S., Serpen, A., Gökmen, V. \& Acar, J. Study of lipoxygenase and peroxidase as indicator enzymes in green beans: change of enzyme activity, ascorbic acid and chlorophylls during frozen storage. Journal of Food Engineering 66, 187-192 (2005).

41. Rodrigo, C., Rodrigo, M., Alvarruiz, A. \& Frígola, A. Inactivation and Regeneration Kinetics of Horseradish Peroxidase Heated at High Temperatures. Journal of Food Protection 60, 961-966 (1997). 42. You, Y., Kang, T. \& Jun, S. Control of Ice Nucleation for Subzero Food Preservation. Food Eng Rev (2020) doi:10.1007/s12393020-09211-6.

43. Xanthakis, E., Le-Bail, A. \& Ramaswamy, H. Development of an innovative microwave assisted food freezing process. Innovative Food Science \& Emerging Technologies 26, 176-181 (2014). 44. Cheng, L., Sun, D.-W., Zhu, Z. \& Zhang, Z. Emerging techniques for assisting and accelerating food freezing processes: A review of recent research progresses. Critical Reviews in Food Science and Nutrition 57, 769-781 (2017).

45. Kobayashi, R. \& Suzuki, T. Effect of supercooling accompanying 
the freezing process on ice crystals and the quality of frozen strawberry tissue. International Journal of Refrigeration 99, 94-100 (2019).

46. Bergquist, S. Å., Gertsson, U. E. \& Olsson, M. E. Influence of growth stage and postharvest storage on ascorbic acid and carotenoid content and visual quality of baby spinach (Spinacia oleracea L.). Journal of the Science of Food and Agriculture 86, 346-355 (2006) 